\title{
The short-term bronchodilator effects of the dual phosphodiesterase 3 and 4 inhibitor RPL554 in COPD
}

\author{
Dave Singh ${ }^{1}$, Katharine Abbott-Banner ${ }^{2}$, Thomas Bengtsson ${ }^{3}$ and \\ Kenneth Newman ${ }^{2}$
}

Affiliations: ${ }^{1}$ Medicines Evaluation Unit, University of Manchester and Manchester University NHS Foundation Trust, Manchester, UK. ${ }^{2}$ Verona Pharma plc, London, UK. ${ }^{3}$ StatMind AB, Lund, Sweden.

Correspondence: Dave Singh, Medicines Evaluation Unit, The Langley Building, University of Manchester and Manchester University NHS Foundation Trust, Southmoor Road, Manchester, M23 9QZ, UK.

E-mail: dsinghameu.org.uk

@ERSpublications

The dual PDE3 and PDE4 inhibitor RPL554 causes additional bronchodilation when combined with commonly used short- or long-acting bronchodilators http://ow.ly/CUYi30lDcYW

Cite this article as: Singh D, Abbott-Banner K, Bengtsson T, et al. The short-term bronchodilator effects of the dual phosphodiesterase 3 and 4 inhibitor RPL554 in COPD. Eur Respir J 2018; 52: 1801074 [https://doi. org/10.1183/13993003.01074-2018].

ABSTRACT We investigated the short-term bronchodilator effects of RPL554 (an inhaled dual phosphodiesterase 3 and 4 inhibitor) combined with other bronchodilators in chronic obstructive pulmonary disease patients with reversibility ( $>150 \mathrm{~mL}$ to short-acting bronchodilators).

Study 1 was a six-way, placebo-controlled crossover study $(\mathrm{n}=36)$ with single doses of RPL554 (6 mg), salbutamol $(200 \mu \mathrm{g})$, ipratropium $(40 \mu \mathrm{g}), \quad$ RPL554 $(6 \mathrm{mg})+$ salbutamol $(200 \mu \mathrm{g}), \quad$ RPL554 (6 mg) +ipratropium $(40 \mu \mathrm{g})$ or placebo. Study 2 was a three-way crossover study $(\mathrm{n}=30)$ of tiotropium $(18 \mu \mathrm{g})$ combined with RPL554 (1.5 or $6 \mathrm{mg}$ ) or placebo for 3 days. Forced expiratory volume in $1 \mathrm{~s}$ (FEV1), lung volumes and specific airway conductance (sGaw) were measured.

In study 1, peak FEV1 change compared with placebo was similar with RPL554, ipratropium and salbutamol (mean 223, 199 and $187 \mathrm{~mL}$, respectively). The peak FEV1 was higher for RPL554+ipratropium versus ipratropium (mean difference $94 \mathrm{~mL} ; \mathrm{p}<0.0001$ ) and RPL554+salbutamol versus salbutamol (mean difference $108 \mathrm{~mL} ; \mathrm{p}<0.0001$ ). In study 2 (day 3), both RPL554 doses caused greater peak FEV1 effects than placebo. The average $\mathrm{FEV}_{(0-12 \mathrm{~h})}$ increase was greater with RPL554 $6 \mathrm{mg}$ only versus placebo (mean difference $65 \mathrm{~mL} ; \mathrm{p}=0.0009$ ). In both studies, lung volumes and $\mathrm{s} G$ aw showed greater RPL554 combination treatment effects versus monotherapy.

RPL554 combined with standard bronchodilators caused additional bronchodilation and hyperinflation reduction.

\section{This article has supplementary material available from erj.ersjournals.com}

Received: June 082018 | Accepted after revision: Aug 222018

These studies are registered at www.clinicaltrials.gov with identifier numbers NCT02542254 and NCT03028142. This article contains considerable details of the group-level data. The protocol, statistical analysis plan and patient-level data can be accessed by contacting Verona Pharma plc.

Copyright OERS 2018. This version is distributed under the terms of the Creative Commons Attribution NonCommercial Licence 4.0. 


\section{Introduction}

RPL554 is a first-in-class, dual inhibitor of both phosphodiesterase (PDE) 3 and 4 isoforms $[1,2]$. PDE3 inhibitors principally target smooth muscle cells to cause bronchodilation [3-5], whereas PDE4 inhibitors exert anti-inflammatory effects across a range of immune cell types [6,7]. RPL554 therefore represents a novel drug class combining bronchodilator and anti-inflammatory effects in a single molecule. Initial clinical trials showed that inhaled RPL554 caused bronchodilation in patients with asthma and chronic obstructive pulmonary disease (COPD), likely due to PDE3 inhibition, and demonstrated significant anti-inflammatory effects in the healthy volunteer lipopolysaccharide (LPS) inhalation model of neutrophilic lung disease, likely due to PDE4 inhibition [2]. However, cell and animal models have shown that combined PDE3 and PDE4 inhibition causes additive or synergistic anti-inflammatory and bronchodilator effects [8]. Inhaled RPL554 delivery minimises systemic exposure, thereby reducing the potential for PDE3- or PDE4-mediated side-effects, and has been well tolerated in early-phase clinical trials to date [2].

While pre-clinical data demonstrate that combining RPL554 with other bronchodilators produces additional bronchodilation $[9,10]$, this concept has not been investigated in COPD clinical trials. The future use of RPL554 in clinical practice is likely to be in conjunction with other bronchodilators. We report two phase II clinical trials in COPD patients investigating the bronchodilator effects of RPL554 combined with other bronchodilators. In one study, RPL554 was combined with short-acting bronchodilators; in another study, RPL554 was combined with the long-acting muscarinic antagonist (LAMA) tiotropium.

\section{Methods}

Subjects

Both studies were performed at the Medicines Evaluation Unit, Manchester, UK (www.clinicaltrials.gov identifiers NCT02542254 and NCT03028142). Inclusion and exclusion criteria are listed in full in the supplementary material. For both studies, patients with a diagnosis of COPD and a post-bronchodilator forced expiratory volume in $1 \mathrm{~s}$ (FEV1) $40-80 \%$ predicted were recruited, and COPD patients with significant cardiovascular disease including angina or recent myocardial infarction were excluded. For study 1, FEV1 reversibility $>150 \mathrm{~mL}$ after inhalation of salbutamol $(200 \mu \mathrm{g})$ and ipratropium $(40 \mu \mathrm{g})$ together was required. For study 2, FEV1 reversibility $>150 \mathrm{~mL}$ after inhalation of salbutamol $(400 \mu \mathrm{g})$ was required. One patient participated in both studies. Ethical approval was obtained and participants provided written informed consent before screening.

\section{Study design}

Study 1 was a randomised, double-blind, placebo-controlled, double-dummy, complete-block six-way crossover study to investigate combination treatment with nebulised RPL554 (6 mg) and salbutamol $(200 \mu \mathrm{g})$ or ipratropium $(40 \mu \mathrm{g})$ compared with salbutamol or ipratropium alone (figure 1a). The salbutamol and ipratropium doses are those approved for COPD patients. Long-acting bronchodilator treatment was withdrawn at screening. There were six treatment visits separated by washout periods of 3-14 days. The pre-dose FEV1 at treatment visits was required to be within $\pm 15 \%$ of the value at the first treatment visit. On each treatment visit, patients received a single dose (two puffs) from a blinded pressurised metered dose inhaler (pMDI) of salbutamol $(200 \mu \mathrm{g})$ or matched placebo followed, within $1 \mathrm{~min}$, by a single dose (two puffs) from a second blinded pMDI of ipratropium ( $40 \mu \mathrm{g})$ or matched placebo. This was followed immediately (within $2 \mathrm{~min}$ ) by a single double-blind dose of either RPL554
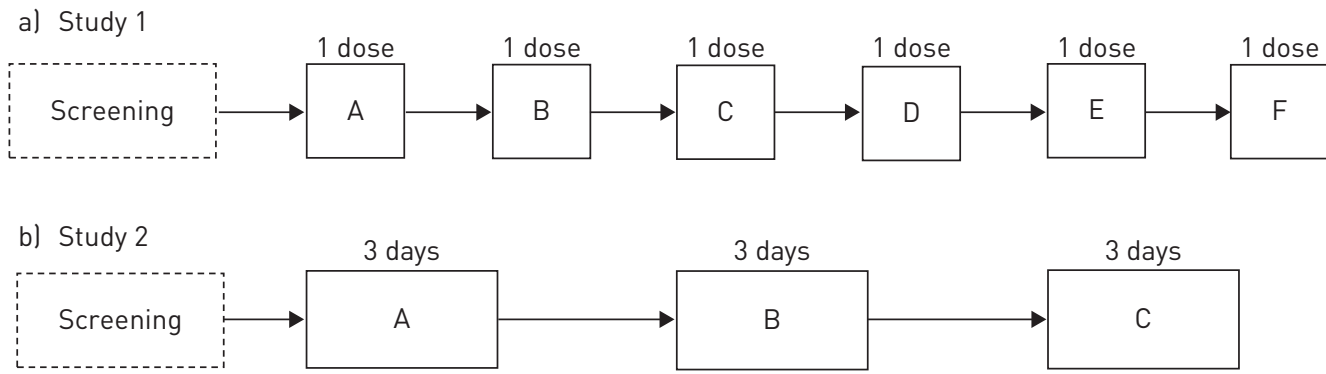

FIGURE 1 Overview of study designs. a) Study 1 randomised treatments (A-F): RPL554 (6 mg), salbutamol $(200 \mu \mathrm{g})$, ipratropium $(40 \mu \mathrm{g})$, RPL554 $(6 \mathrm{mg})+$ salbutamol $(200 \mu \mathrm{g})$, RPL554 (6 mg)+ipratropium $(40 \mu \mathrm{g})$ or placebo. b) Study 2 randomised treatments $(A-C)$ : tiotropium $(18 \mu \mathrm{g})$ once daily and RPL554 $(6 \mathrm{mg})$ twice daily, tiotropium $(18 \mu \mathrm{g})$ once daily and RPL554 $(1.5 \mathrm{mg})$ twice daily or tiotropium $(18 \mu \mathrm{g})$ once daily and placebo twice daily. 
$(6 \mathrm{mg})$ or placebo. Spirometry was performed pre-dose and at various times up to $12 \mathrm{~h}$ post-dose. Whole-body plethysmography was performed pre-dose and up to $4 \mathrm{~h}$ post-dose to obtain measurements of functional residual capacity (FRC), residual volume (RV), total lung capacity and specific airway conductance (sGaw).

Study 2 was a randomised, double-blind, placebo-controlled, complete-block three-way crossover study to investigate combination treatment with nebulised RPL554 (1.5 or $6 \mathrm{mg}$ ) and tiotropium (18 $\mu \mathrm{g}$ using Handihaler; Boehringer Ingelheim Pharmaceuticals, Ridgefield, CT, USA) compared with tiotropium alone (figure $1 \mathrm{~b}$ ). Long-acting bronchodilator treatment was withdrawn at screening. There were three treatment visits separated by washout periods of 7-21 days. On each treatment visit, patients received one of the following treatments for 2 days and on the morning of day 3: 1) tiotropium (18 $\mu \mathrm{g})$ once daily and RPL554 (6 mg) twice daily (tiotropium+RPL554 $6 \mathrm{mg}$ ), 2) tiotropium (18 $\mu \mathrm{g}$ ) once daily and RPL554 $(1.5 \mathrm{mg})$ twice daily (tiotropium+RPL554 $1.5 \mathrm{mg})$ or 3) tiotropium $(18 \mu \mathrm{g})$ once daily and placebo twice daily (tiotropium+placebo).

Tiotropium was administered open label, while RPL554 or placebo was administered double blind. Spirometry was performed on days 1 and 3 at pre-dose and at various times up to $12 \mathrm{~h}$ post-dose, and on day 2 at pre-dose and up to $4 \mathrm{~h}$ post-dose. Whole-body plethysmography was performed at pre-dose on day 1 and at pre-dose and $1.25 \mathrm{~h}$ post-dose on day 2 .

For both studies, patients using inhaled corticosteroids were allowed to continue this treatment during the study. Patients were allowed to use short-acting bronchodilators throughout, but these were withheld for at least $8 \mathrm{~h}$ prior to spirometry. RPL554 manufacture and administration using a PARI LC Sprint (PARI, West Byfleet, UK) jet nebuliser is described in the supplementary material. The RPL554 doses were selected based on the results of a preliminary study [11]. Spirometry assessments were performed in accordance with guidelines with three technically acceptable measurements recorded [12]; predicted values were calculated using European Community for Coal and Steel reference equations [13].

\section{Statistical analysis}

Sample size calculations are given in the supplementary material. The study 1 primary end-points were change from baseline in peak and average FEV1 over $8 \mathrm{~h}$ comparing RPL554+salbutamol versus salbutamol and RPL554+ipratropium versus ipratropium. The study 2 primary end-points were change from baseline (pre-dose day 1) in peak and average FEV1 over $12 \mathrm{~h}$ on day 3 comparing RPL554 versus placebo. For both studies, the secondary end-points included onset of action (defined as time to reach $10 \%$ increase in FEV1 from baseline), forced vital capacity (FVC), body plethysmography measurements (FRC, $\mathrm{RV}$ and sGaw) and safety. ANCOVA models were used as described in the supplementary material.

\section{Results}

For both studies, flow diagrams showing the number of patients screened, reasons for screen failure and withdrawals are given in the supplementary material.

\begin{tabular}{|c|c|c|}
\hline & Study 1 & Study 2 \\
\hline Subjects & 36 & 30 \\
\hline \multicolumn{3}{|l|}{ Sex } \\
\hline Male & 19 & 17 \\
\hline Female & 17 & 13 \\
\hline Age years & $61.3 \pm 5.2$ & $62.0 \pm 7.0$ \\
\hline BMI $\mathrm{kg} \cdot \mathrm{m}^{-2}$ & $25.7 \pm 3.1$ & $26.4 \pm 3.6$ \\
\hline FEV $1 \%$ pred & $50.4 \pm 12.2$ & $50.8 \pm 10.4$ \\
\hline FEV 1 L & $1.44 \pm 0.5$ & $1.52 \pm 0.7$ \\
\hline Bronchodilator reversibility \% & $17.4 \pm 11.1^{\#}$ & $19.5 \pm 8.6^{\pi}$ \\
\hline \multicolumn{3}{|l|}{ Smoking status } \\
\hline Current smoker & 24 & 10 \\
\hline Ex-smoker & 12 & 20 \\
\hline Cigarette pack-years & $47.1 \pm 19.3$ & $38.6 \pm 17.2$ \\
\hline
\end{tabular}

Data are presented as $\mathrm{n}$ or mean \pm SD. BMI: body mass index; FEV1: forced expiratory volume in $1 \mathrm{~s}$. Prebronchodilator values shown. ${ }^{\#}$ : 30 min post-salbutamol and ipratropium; ${ }^{\text {? }}: 30$ min post-salbutamol. 
Study 1

Table 1 lists the characteristics of the 36 enrolled COPD patients; the mean post-bronchodilator FEV 1 was $58.3 \%$ predicted with $17.4 \%$ reversibility. Six patients did not complete the study: two patients were withdrawn due to chest infections, while four patients failed to meet the criteria for pre-dose FEV 1 variability and were withdrawn.

FEV 1

The change from baseline in peak FEV1 compared with placebo was similar with RPL554 (mean $223 \mathrm{~mL}$ ), ipratropium bromide (mean $199 \mathrm{~mL}$ ) and salbutamol (mean $187 \mathrm{~mL}$ ) (figure 2a), with no differences between treatments $(p>0.05)$ (table 2$)$. The combination of RPL554 with ipratropium bromide caused a greater increase in peak FEV1 compared with placebo (mean $292 \mathrm{~mL}$; $<0.0001$ ) and compared with ipratropium alone (mean $94 \mathrm{~mL}$; p $<0.0001$ ). RPL554 combined with salbutamol caused a greater peak FEV1 compared with placebo (mean $295 \mathrm{~mL}$; p <0.0001) and compared with salbutamol alone (mean $108 \mathrm{~mL} ; \mathrm{p}<0.0001)$.

The average $\mathrm{FEV}_{(0-8 \mathrm{~h})}$ increase compared with placebo was similar for RPL554 (mean $169 \mathrm{~mL}$ ) and ipratropium (mean $165 \mathrm{~mL}$ ), while RPL554 was statistically superior to salbutamol (mean $123 \mathrm{~mL}$; $\mathrm{p}=0.014$ ) (figure $2 \mathrm{~b}$ and statistical analysis shown in table 2). RPL554 combined with ipratropium caused a mean increase of $229 \mathrm{~mL}$ compared with placebo $(\mathrm{p}<0.0001)$ and $64 \mathrm{~mL}$ compared with ipratropium alone $(\mathrm{p}=0.0006)$. RPL554 combined with salbutamol caused a mean increase of $235 \mathrm{~mL}$ compared with placebo $(\mathrm{p}<0.0001)$ and $112 \mathrm{~mL}$ compared with salbutamol alone $(\mathrm{p}<0.0001)$

The median time of onset of action ( $\geqslant 10 \%$ increase from baseline) for RPL554 was 14.6 min, while for ipratropium bromide and salbutamol this was 18.4 and $6.0 \mathrm{~min}$, respectively. RPL554 administered in combination with either salbutamol or ipratropium bromide reduced the median time of onset to $3.6 \mathrm{~min}$ ( $\mathrm{p}=0.009$ versus salbutamol alone) and $4.8 \mathrm{~min}$ ( $\mathrm{p}<0.0001$ versus ipratropium bromide alone), respectively.

Analysis of peak FVC and average $\mathrm{FVC}_{(0-8 \mathrm{~h})}$ showed greater effects of RPL554 combined with another bronchodilator compared with a bronchodilator alone (analysis shown in supplementary tables S1 and S2).

\section{Body plethysmography}

Each treatment alone reduced RV to a similar extent (figure 3a). The combination of RPL554 with ipratropium bromide caused a $695 \mathrm{~mL}$ reduction in $\mathrm{RV}$ at $1 \mathrm{~h}$, which was significantly greater than ipratropium alone (treatment ratio $0.91,95 \%$ CI $0.88-0.95 ; \mathrm{p}<0.001$ ). Likewise, RPL554 with salbutamol caused a significantly greater reduction in RV than salbutamol alone at both 1 and $4 \mathrm{~h}$. For sGaw, the effects of combination treatment involving RPL554 were significantly greater than ipratropium or salbutamol alone (treatment ratios at $1 \mathrm{~h}: 1.18,95 \%$ CI $1.08-1.28 ; \mathrm{p}<0.001$ and $1.20,95 \%$ CI $1.11-1.31$; $\mathrm{p}<0.001$, respectively) (figure $3 \mathrm{~b}$ ). The FRC results are shown in supplementary table $\mathrm{S} 3$; there was a greater effect of combination treatment involving RPL554 than ipratropium alone or salbutamol alone (e.g. treatment ratios at $4 \mathrm{~h}: 0.96,95 \% \mathrm{CI} 0.94-0.99 ; \mathrm{p}=0.006$ and $0.97,95 \% \mathrm{CI} 0.94-0.99 ; \mathrm{p}=0.01$, respectively).

Safety

RPL554 was well tolerated alone or in combination with salbutamol or ipratropium with a similar rate of adverse events compared with placebo (table 3 ).

\section{Study 2}

Table 1 lists the characteristics of the 30 enrolled COPD patients; the mean post-bronchodilator FEV 1 was $60.1 \%$ predicted with $19.5 \%$ reversibility. Four patients did not complete the study: two patients were withdrawn because of worsening COPD symptoms, one patient withdrew with pneumonia and one patient withdrew consent.

\section{FEV1}

The FEV1 change from baseline (pre-dose on day 1 ) over $12 \mathrm{~h}$ on day 3 is shown in figure $4 \mathrm{a}$. The peak FEV1 changes from baseline for tiotropium combined with placebo or RPL554 1.5 or $6 \mathrm{mg}$ were 373, 477 and $500 \mathrm{~mL}$, respectively (figure $4 \mathrm{~b}$ ). The effects of tiotropium+RPL554 1.5 and $6 \mathrm{mg}$ were significantly greater than tiotropium+placebo $\left(\mathrm{p}=0.002\right.$ and $\mathrm{p}<0.0001$, respectively). The average $\mathrm{FEV}_{(0-12 \mathrm{~h})}$ increase on day 3 was greater with tiotropium+RPL554 $6 \mathrm{mg}(331 \mathrm{~mL})$ compared with tiotropium+placebo ( $266 \mathrm{~mL} ; \mathrm{p}=0.0009$ ) (figure $4 \mathrm{c}$ ). There was no difference for tiotropium+RPL554 $1.5 \mathrm{mg}(317 \mathrm{~mL}$ ) versus tiotropium+placebo $(\mathrm{p}=0.09)$.

The mean change in morning trough $\mathrm{FEV}_{1}$ on day 3 compared with baseline (day 1 pre-dose) was greater with tiotropium+RPL554 $6 \mathrm{mg}(230 \mathrm{~mL})$ compared with tiotropium+placebo (114 mL; p=0.0003), while there was no difference for tiotropium+RPL554 $1.5 \mathrm{mg}(168 \mathrm{~mL})$ versus tiotropium+placebo $(\mathrm{p}=0.35)$. 
a)

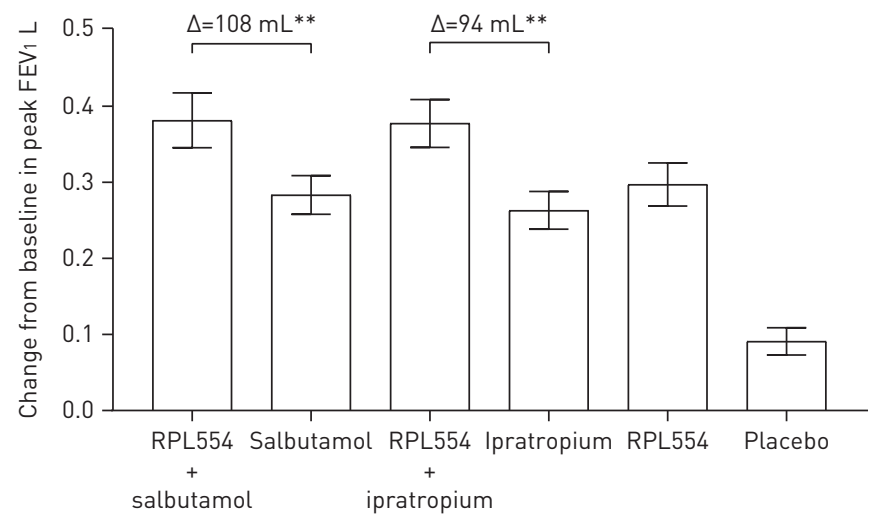

b)

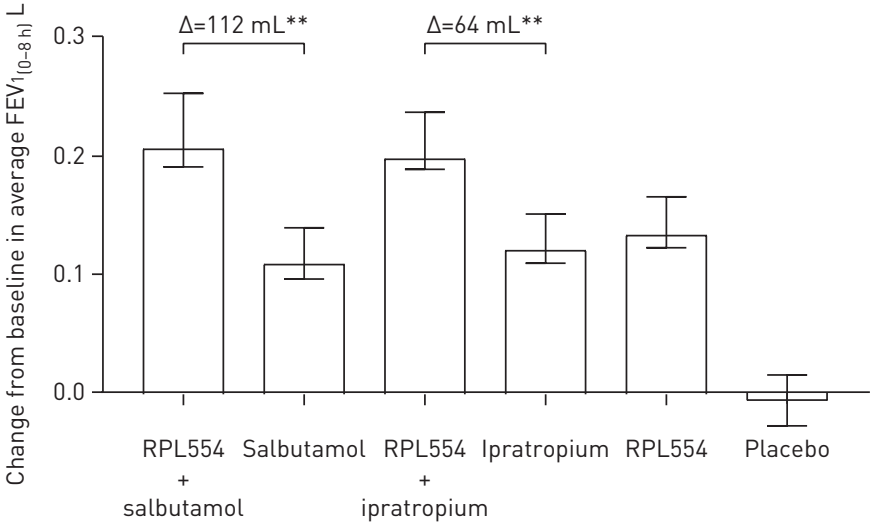

FIGURE 2 Study 1: forced expiratory volume in $1 \mathrm{~s}$ (FEV1) changes caused by RPL554 (6 mg), salbutamol (200 $\mu \mathrm{g})$ and ipratropium (40 $\mu \mathrm{g})$ alone and in combination (single doses). a) Peak FEV1 and b) average FEV $1_{(0-8 \mathrm{~h})}$. Data are presented as mean \pm SEM. ${ }^{* *}: p<0.01$.

On day 1, there were significantly greater FEV1 improvements with tiotropium+RPL554 6 mg compared with tiotropium+placebo, while tiotropium+RPL554 $1.5 \mathrm{mg}$ was not significantly different to tiotropium +placebo; these results are shown in the supplementary material. Notably, for peak FEV1 the mean difference between tiotropium+RPL554 $6 \mathrm{mg}$ and tiotropium+placebo was $95 \mathrm{~mL}$ ( $\mathrm{p}=0.0039)$. The median time of onset of action on day 1 for tiotropium+RPL554 1.5 and $6 \mathrm{mg}$ was 4.2 and $4.6 \mathrm{~min}$, respectively, compared with $37.6 \mathrm{~min}$ for tiotropium+placebo ( $\mathrm{p}<0.0001$ for comparisons of RPL554 versus placebo).

Analysis of peak FVC and average $\mathrm{FVC}_{(0-12 \mathrm{~h})}$ showed a greater effect of RPL554 $6 \mathrm{mg}$ compared with placebo (shown in the supplementary material).

\section{Body plethysmography}

On day 2 , there was a reduction in RV with all treatments at $1.25 \mathrm{~h}$ post-dose (figure $5 \mathrm{a}$ ). Tiotropium+RPL554 $6 \mathrm{mg}$ caused a significantly greater effect than tiotropium+placebo ( $\mathrm{p}=0.0048$ ), while the effect of tiotropium + RPL554 $1.5 \mathrm{mg}$ was not significant $(\mathrm{p}=0.071)$. The improvements in FRC were significantly greater with tiotropium+RPL554 1.5 and $6 \mathrm{mg}$ compared with tiotropium+placebo (treatment ratios: 0.96, 95\% CI 0.94-0.99; $\mathrm{p}=0.027$ and $0.97,95 \%$ CI $0.95-1.00 ; \mathrm{p}=0.047$, respectively). Similarly, sGaw improvements were significantly greater with tiotropium+RPL554 1.5 and $6 \mathrm{mg}$ compared with tiotropium+placebo (treatment ratios: 1.24, 95\% CI $1.14-1.35$ and $1.31,95 \%$ CI $1.20-1.43$, respectively; $\mathrm{p}<0.0001$ for both comparisons) (figure $5 \mathrm{~b}$ ).

\section{Safety}

Tiotropium+RPL554 was well tolerated with a similar rate of adverse events compared with tiotropium +placebo (table 4). Withdrawals due to COPD worsening occurred during washout periods and were not attributed to RPL554.

TABLE 2 Statistical analysis of treatment effects in study 1

\begin{tabular}{|c|c|c|c|c|}
\hline & \multicolumn{2}{|c|}{$\begin{array}{c}\text { Treatment difference: } \\
\text { peak FEV } \mathrm{L}\end{array}$} & \multicolumn{2}{|c|}{$\begin{array}{l}\text { Treatment difference: } \\
\text { FEV } 1 \text { average effect } 0-8 \mathrm{~h} L\end{array}$} \\
\hline & Difference $(95 \% \mathrm{CI})$ & p-value & Difference $(95 \% \mathrm{Cl})$ & p-value \\
\hline Salbutamol versus placebo & $0.187(0.142-0.232)$ & $<0.001$ & $0.123(0.087-0.159)$ & $<0.001$ \\
\hline Ipratropium versus placebo & $0.199(0.153-0.244)$ & $<0.001$ & $0.165(0.128-0.201)$ & $<0.001$ \\
\hline RPL554 versus placebo & $0.223(0.178-0.269)$ & $<0.001$ & $0.165(0.133-0.206)$ & $<0.001$ \\
\hline Salbutamol+RPL554 versus placebo & $0.292(0.250-0.340)$ & $<0.001$ & $0.235(0.199-0.271)$ & $<0.001$ \\
\hline RPL554 versus ipratropium & $0.024(-0.021-0.070)$ & 0.294 & $0.004(-0.032-0.041)$ & 0.8148 \\
\hline Salbutamol versus ipratropium & $-0.012(-0.057-0.034)$ & 0.614 & $-0.042(-0.078-0.005)$ & 0.0245 \\
\hline Salbutamol+RPL554 versus salbutamol & $0.108(0.063-0.153)$ & $<0.001$ & $0.112(0.076-0.148)$ & $<0.001$ \\
\hline Ipratropium+RPL554 versus ipratropium & $0.094(0.049-0.139)$ & $<0.001$ & $0.064(0.028-0.100)$ & 0.0006 \\
\hline
\end{tabular}

FEV1: forced expiratory volume in $1 \mathrm{~s}$. 

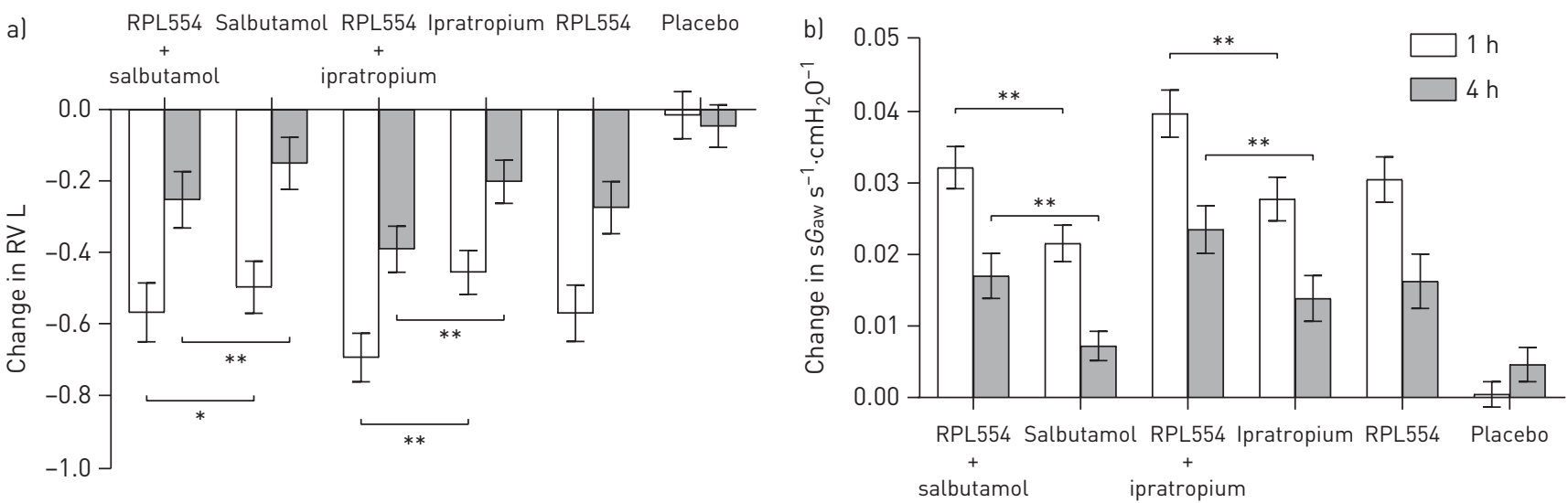

FIGURE 3 Study 1: a) Residual volume (RV) and b) specific airway conductance (sGaw) changes caused by RPL554 (6 mg), salbutamol (200 $\mu \mathrm{g}$ ) and ipratropium $\left(40 \mu \mathrm{g}\right.$ ) alone and in combination (single doses). Data are presented as mean \pm SEM. ${ }^{*}: p<0.05 ;{ }^{* *}: p<0.01$.

\section{Discussion}

We show that RPL554 combined with short-acting bronchodilators or tiotropium caused additional improvements in FEV1 and hyperinflation in reversible COPD patients. In study 1, a single dose of RPL554 $6 \mathrm{mg}$ in addition to salbutamol or ipratropium caused significantly greater peak FEV1 improvements compared with either short-acting bronchodilator alone. In study 2, additional improvements in peak, trough and average (0-12 h) FEV1 were observed when RPL554 $6 \mathrm{mg}$ was administered with tiotropium for 3 days.

Study 1 was designed to test the mechanistic hypothesis that RPL554 could provide additional bronchodilation in combination with either a $\beta_{2}$-agonist or a muscarinic antagonist. This can be regarded as a "proof-of-pharmacology" study to investigate effects caused by different mechanisms of action alone or combined. This study was focused on peak FEV1, and showed similar effects of RPL554, salbutamol and ipratropium administered alone, suggesting that RPL554 causes clinically relevant bronchodilation. The additional effects of RPL554 when combined with short-acting bronchodilators provided mechanistic insights that PDE3/4 inhibition, which increases cAMP levels [7], can cause additional effects when combined with a $\beta_{2}$-agonist, which also acts through regulation of cAMP levels [10], or a muscarinic antagonist. Study 1 therefore provided mechanistic support to investigate RPL554 further in combination with long-acting bronchodilator treatment.

TABLE 3 Adverse events: study 1

Placebo RPL554 (6 mg) Salbutamol $(200 \mu \mathrm{g}) \quad$ Salbutamol $(200 \mu \mathrm{g}) \quad$ Ipratropium $(40 \mu \mathrm{g}) \quad$ Ipratropium $(40 \mu \mathrm{g})$ RPL554 (6 mg)

RPL554 (6 mg)

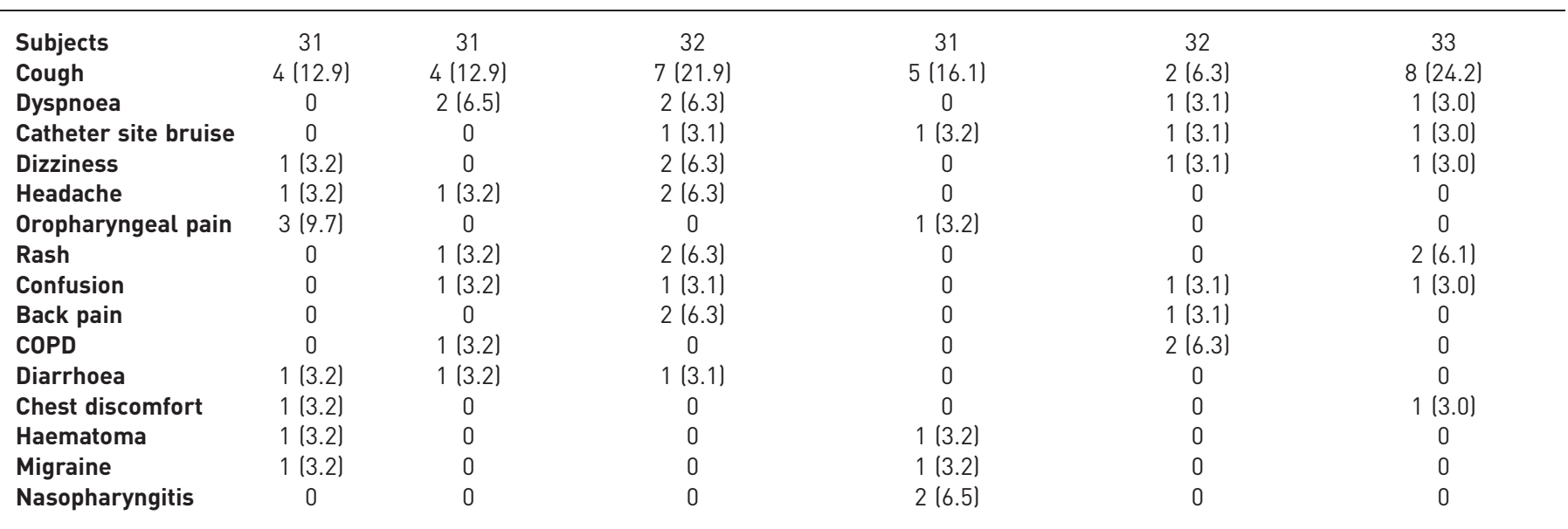

Data are presented as $\mathrm{n}$ or $\mathrm{n}(\%)$. COPD: chronic obstructive pulmonary disease. Treatment emergent adverse events reported by more than one patient are presented. Patients may have experienced the same adverse event following different study treatments. 


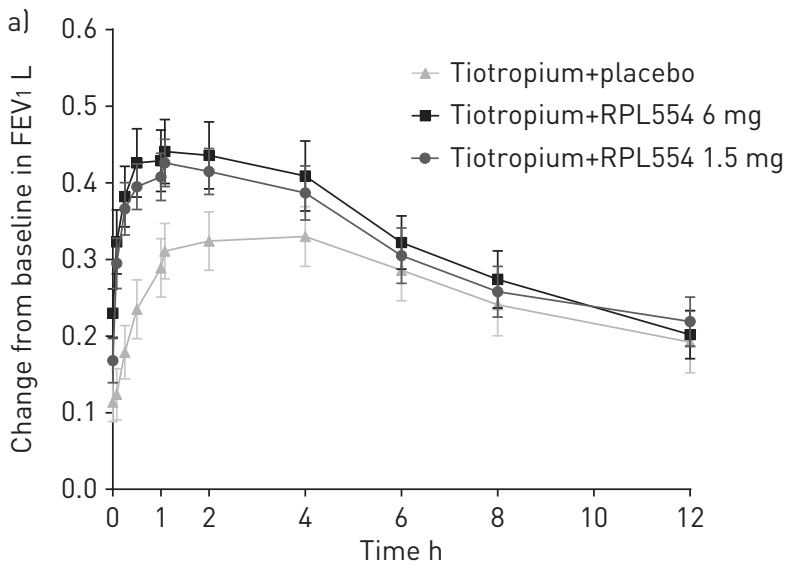

b)

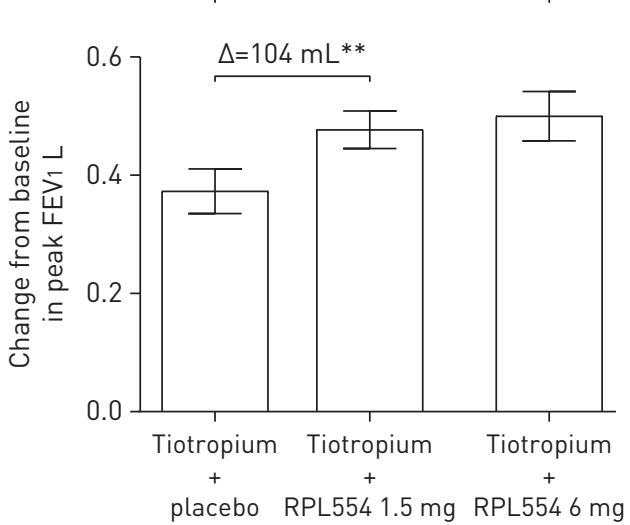

c)

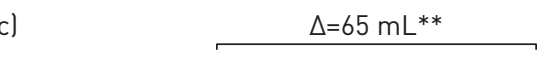

FIGURE 4 Study 2: lung function (forced expiratory volume in $1 \mathrm{~s}\left(F E V_{1}\right)$ ) on day 3. a) FEV1 change from baseline (pre-dose on day 1). b) Peak FEV 1 change from baseline (pre-dose on day 1) caused by tiotropium $(18 \mu \mathrm{g})$, tiotropium $(18 \mu \mathrm{g})+\mathrm{RPL5} 54(1.5 \mathrm{mg})$ and tiotropium $(18 \mu \mathrm{g})+\mathrm{RPL} 554(6 \mathrm{mg})$. c) Average FEV $1_{(0-12 \mathrm{~h})}$ change from baseline (pre-dose on day 1) caused by tiotropium $(18 \mu \mathrm{g})$, tiotropium $(18 \mu \mathrm{g})+\mathrm{RPL} 554(1.5 \mathrm{mg})$ and tiotropium $(18 \mu \mathrm{g})+\mathrm{RPL} 554(6 \mathrm{mg})$. Data are presented as mean \pm SEM. ${ }^{* *}$ : $p<0.01$.

Tiotropium was chosen for study 2 as it is a commonly used long-acting bronchodilator. On day 3 , the magnitude of additional bronchodilation caused by RPL554 was $116 \mathrm{~mL}$ at trough (pre-dose), suggesting that twice-daily RPL554 dosing provides sustained additional bronchodilation persisting for $12 \mathrm{~h}$ post-dose. RPL554 $6 \mathrm{mg}$ had a greater effect on FEV1 parameters than the $1.5 \mathrm{mg}$ dose and appears to be
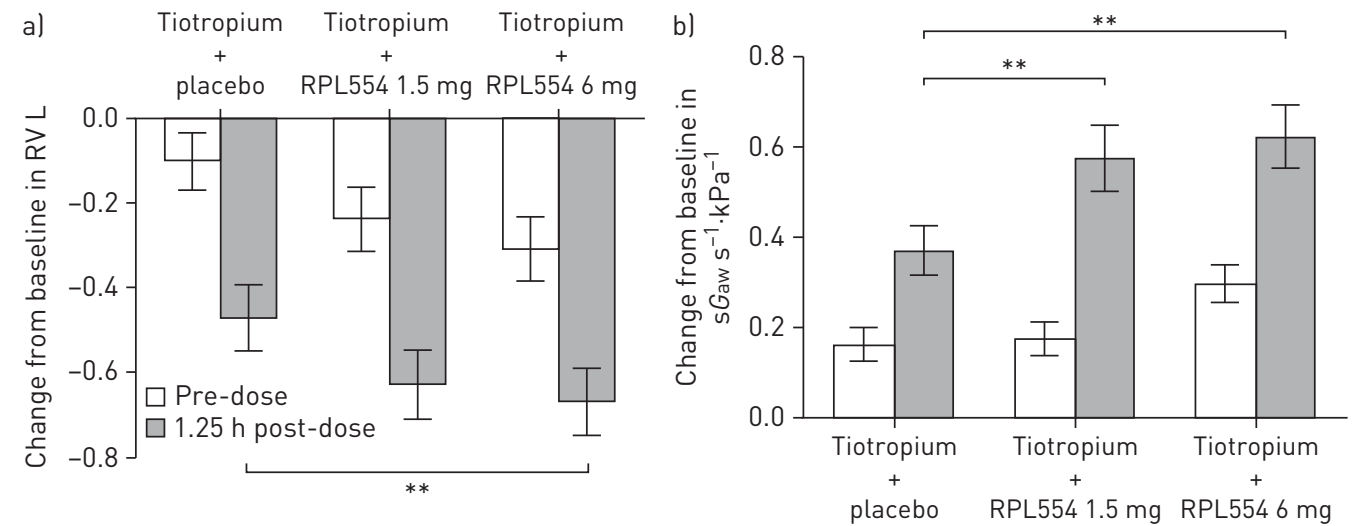

FIGURE 5 Study 2: a) Residual volume (RV) and b) specific airway conductance (sGaw) changes on day 3 caused by tiotropium $(18 \mu \mathrm{g})$, tiotropium $(18 \mu \mathrm{g})+\mathrm{RPL} 554(1.5 \mathrm{mg})$ and tiotropium $(18 \mu \mathrm{g})+\mathrm{RPL} 554(6 \mathrm{mg})$. The change from baseline (pre-dose on day 1) is shown. Data are presented as mean \pm SEM. ${ }^{* *}: p<0.01$. 
TABLE 4 Adverse events: study 2

System organ class preferred term"

\begin{tabular}{|c|c|c|c|c|c|c|}
\hline & \multicolumn{2}{|c|}{$\stackrel{+}{\operatorname{RPL} 554(1.5 \mathrm{mg})}$} & \multicolumn{2}{|c|}{$\stackrel{+}{\text { RPL554 (6 mg) }}$} & \multicolumn{2}{|c|}{$\stackrel{+}{+}$} \\
\hline Total TEAEs & 16 & $12(41.4)$ & 20 & $12(44.4)$ & 17 & $12(42.9)$ \\
\hline General disorders and administration site conditions & 5 & 4 (13.8) & 4 & $4(14.8)$ & 7 & $6(21.4)$ \\
\hline Medical device site reaction & 4 & $4(13.8)$ & 1 & $1(3.7)$ & 4 & $4(14.3)$ \\
\hline Chest discomfort & 1 & $1(3.4)$ & 1 & $1(3.7)$ & 2 & $2(7.1)$ \\
\hline Headache & 2 & $2(6.9)$ & 8 & $5(18.5)$ & 3 & $3(10.7)$ \\
\hline Respiratory, thoracic and mediastinal disorders & 3 & $3(10.3)$ & 3 & $3(11.1)$ & 3 & $2(7.1)$ \\
\hline Dyspnoea & 1 & $1(3.4)$ & 1 & $1(3.7)$ & 3 & $2(7.1)$ \\
\hline Infections and infestations & 1 & $1(3.4)$ & 1 & $1(3.7)$ & 3 & $2(7.1)$ \\
\hline Musculoskeletal and connective tissue disorders & 2 & $2(6.9)$ & 2 & $2(7.4)$ & 0 & 0 \\
\hline
\end{tabular}

Data are presented as $\mathrm{n}$ or $\mathrm{n}(\%)$. TEAE: treatment emergent adverse event. TEAEs reported by more than one patient are presented. Patients may have experienced the same adverse event following different study treatments. \#: MedDRA terms (www.meddra.org).

a suitable twice-daily dose for further investigation. Although study 2 demonstrated an additional effect of RPL554 when administered with a LAMA, it would also be relevant to investigate the effects of RPL554 administered with a long-acting $\beta_{2}$-adrenergic agonist (LABA) or a LAMA/LABA combination.

Hyperinflation and gas trapping are major causes of the sensation of dyspnoea, and improvements in lung volumes can improve dyspnoea and exercise performance [14]. RV, a measurement of gas trapping, was reduced by RPL554 in both studies, suggesting a possible effect of RPL554 on small airway function. The onset of bronchodilator action was also faster in both studies when RPL554 was used in combination. A faster onset of bronchodilation may be important to some patients in terms of providing symptom relief.

Pre-clinical studies using human isolated bronchial smooth muscle preparations have demonstrated that RPL554 added to other bronchodilators caused additional bronchodilation, with some evidence of synergistic effects when combined with a muscarinic antagonist [9, 10, 15]. In our clinical trials, additional bronchodilation was observed when using RPL554 in combination with other bronchodilators. While the RPL554 bronchodilator effects are likely to be mainly attributable to PDE3 inhibition, pre-clinical studies have suggested that PDE4 inhibition relaxes inherent tone in isolated human airway tissue $[16,17]$.

Roflumilast is an orally administered PDE4 inhibitor that reduces exacerbation rates, but the frequency of side-effects, including nausea, weight loss and gastrointestinal disturbance, limits its use in clinical practice $[18,19]$. RPL554 was well tolerated in these short-term studies. Clinical trials with a longer duration and larger sample size are needed for proper safety evaluation. RPL554 has the potential for fewer side-effects compared with orally administered PDE4 inhibitors due to reduced systemic exposure, although there may also be intrinsic differences in the pharmacological potential of these different molecules to cause side-effects.

The limitations of the studies reported here include: 1) longer studies are needed to evaluate effects on key clinical end-points, including symptoms and exacerbations, and to properly evaluate safety; 2) the COPD patients included had evidence of reversibility $(>150 \mathrm{~mL})$ at screening and the effects of RPL554 in broader population groups need to be studied; 3) the effects of RPL554 in addition to combination treatments that are commonly used in clinical practice remain to be studied, such as LAMA/LABA or triple (inhaled corticosteroid+LABA+LAMA) combinations; and 4) while the anti-inflammatory effects of RPL554 have previously been demonstrated in the LPS challenge model in healthy volunteers [2], further studies of anti-inflammatory effects in COPD patients would be informative.

In conclusion, RPL554 provided additional bronchodilation, reduced gas trapping, improved airway conductance and showed a more rapid onset of action when administered in combination with either a $\beta_{2}$-agonist or muscarinic antagonist. These short-term bronchodilator studies provide support to further study RPL554 in longer-term COPD studies focused on other end-points, including symptoms and exacerbations. 
Conflict of interest: D. Singh reports receiving personal fees from Verona during the conduct of the study; and personal fees from Apellis, Cipla, Genentech, Peptinnovate and Skyepharma, and grants and personal fees from AstraZeneca, Boehringer Ingelheim, Chiesi, GlaxoSmithKline, Glenmark, Menarini, Merck, Mundipharma, Novartis, Pfizer, Pulmatrix, Teva, Therevance and Verona, outside the submitted work. K. Abbott-Banner has nothing to disclose. T. Bengtsson reports receiving personal fees for statistical consultancy from Verona Pharma plc during the conduct of the study and outside the submitted work. K. Newman was previously an employee of Verona Pharma.

Support statement: This study was supported by Verona Pharma plc.

\section{References}

1 Boswell-Smith V, Spina D, Oxford AW, et al. The pharmacology of two novel long-acting phosphodiesterase 3/4 inhibitors, RPL554 [9,10-dimethoxy-2(2,4,6-trimethylphenylimino)-3-( $N$-carbamoyl-2-aminoethyl)-3,4,6,7tetrahydro-2H-pyrimido[6,1-a]isoquinolin-4-one] and RPL565 [6,7-dihydro-2-(2,6-diisopropylphenoxy)9,10-dimethoxy-4H-pyrimido[6,1-a] isoquinolin-4-one]. J Pharmacol Exp Ther 2006; 318: 840-848.

2 Franciosi LG, Diamant Z, Banner KH, et al. Efficacy and safety of RPL554, a dual PDE3 and PDE4 inhibitor, in healthy volunteers and in patients with asthma or chronic obstructive pulmonary disease: findings from four clinical trials. Lancet Respir Med 2013; 1: 714-727.

3 de Boer J, Philpott AJ, van Amsterdam RG, et al. Human bronchial cyclic nucleotide phosphodiesterase isoenzymes: biochemical and pharmacological analysis using selective inhibitors. Br J Pharmacol 1992; 106: 1028-1034.

4 Bardin PG, Dorward MA, Lampe FC, et al. Effect of selective phosphodiesterase 3 inhibition on the early and late asthmatic responses to inhaled allergen. Br J Clin Pharmacol 1998; 45: 387-391.

5 Myou S, Fujimura M, Kamio Y, et al. Bronchodilator effect of inhaled olprinone, a phosphodiesterase 3 inhibitor, in asthmatic patients. Am J Respir Crit Care Med 1999; 160: 817-820.

6 Page CP, Spina D. Phosphodiesterase inhibitors in the treatment of inflammatory diseases. Handb Exp Pharmacol 2011: 391-414.

7 Banner KH, Press NJ. Dual PDE3/4 inhibitors as therapeutic agents for chronic obstructive pulmonary disease. $\mathrm{Br}$ J Pharmacol 2009; 157: 892-906.

8 Abbott-Banner KH, Page CP. Dual PDE3/4 and PDE4 inhibitors: novel treatments for COPD and other inflammatory airway diseases. Basic Clin Pharmacol Toxicol 2014; 114: 365-376.

9 Calzetta L, Cazzola M, Page CP, et al. Pharmacological characterization of the interaction between the dual phosphodiesterase (PDE) 3/4 inhibitor RPL554 and glycopyrronium on human isolated bronchi and small airways. Pulm Pharmacol Ther 2015; 32: 15-23.

10 Calzetta L, Page CP, Spina D, et al. Effect of the mixed phosphodiesterase 3/4 inhibitor RPL554 on human isolated bronchial smooth muscle tone. J Pharmacol Exp Ther 2013; 346: 414-423.

11 Singh D, Banner K, Newman K. RPL554, an inhaled PDE3/4 inhibitor, causes profound and sustained bronchodilation in healthy volunteers and COPD patients. Eur Respir J 2016; 48: PA4052.

12 Miller MR, Hankinson J, Brusasco V, et al. Standardisation of spirometry. Eur Respir J 2005; 26: 319-338.

13 Quanjer PH, Tammeling GJ, Cotes JE, et al. Lung volumes and forced ventilatory flows. Eur Respir J 1993; 6: Suppl. 16, 5-40.

14 Langer D, Ciavaglia CE, Neder JA, et al. Lung hyperinflation in chronic obstructive pulmonary disease: mechanisms, clinical implications and treatment. Expert Rev Respir Med 2014; 8: 731-749.

15 Venkatasamy R, Spina D. Novel relaxant effects of RPL554 on guinea pig tracheal smooth muscle contractility. $\mathrm{Br}$ J Pharmacol 2016; 173: 2335-2351.

16 Naline E, Qian Y, Advenier C, et al. Effects of RP 73401, a novel, potent and selective phosphodiesterase type 4 inhibitor, on contractility of human, isolated bronchial muscle. Br J Pharmacol 1996; 118: 1939-1944.

17 Schmidt DT, Watson N, Dent G, et al. The effect of selective and non-selective phosphodiesterase inhibitors on allergen- and leukotriene $\mathrm{C}_{4}$-induced contractions in passively sensitized human airways. Br J Pharmacol 2000; 131: 1607-1618.

18 Fabbri LM, Calverley PM, Izquierdo-Alonso JL, et al. Roflumilast in moderate-to-severe chronic obstructive pulmonary disease treated with longacting bronchodilators: two randomised clinical trials. Lancet 2009; 374: 695-703.

19 Rennard SI, Calverley PM, Goehring UM, et al. Reduction of exacerbations by the PDE4 inhibitor roflumilast the importance of defining different subsets of patients with COPD. Respir Res 2011; 12: 18. 